\title{
ABAETETUBA-PA: MENINA DE LAÇO DE FITA - A TERNURA COMO ESSÊNCIA, A LUTA COMO PRINCÍPIO E O EMPODERAMENTO COMO ESTRATÉGIA PARA A CIDADANIA
}

Flávio Alberto de Andrade Goulart, Júlio Manuel Suarez Jimenez, Kellen da Costa Barbosa, Laurindo Campos de Lima e Maria Lucilene Ribeiro das Chagas

\section{RESUMO}

Este artigo descreve a experiência de empoderamento da população como estratégia para construção de cidadania visando o enfrentamento de problemas de saúde no âmbito da APS em Abaetetuba, Pará.

Palavras-chave: Atenção Primária à Saúde; Acesso; Prêmio APS.

\section{ABSTRACT}

This article describes the experience of empowering the population as a strategy for reinforce citizenship in order to face health problems within PHC in Abaetetuba, Pará.

Keywords: Prmary Health Care; Access; PHC Prize.
Revista da Rede APS 2020

Publicada em: 04/09/2020

DOI:10.14295/aps.v2i3.151

Flávio Alberto de Andrade Goulart

(Organização Pan-Americana de Saúde)

Júlio Manuel Suarez Jimenez (Organização Pan-Americana de Saúde)

Kellen da Costa Barbosa (Secretaria Municipal de Saúde de Abaetetuba)

Laurindo Campos de Lima (Secretaria Municipal de Saúde de Abaetetuba)

Maria Lucilene Ribeiro das Chagas

(Secretaria Municipal de Saúde de Abaetetuba)

Correspondência para:

Flávio Goulart goulart.fa@gmail.com

Artigo premiado no concurso "Prêmio APS Forte para o SUS Acesso Universal" - selecionado por uma equipe de jurados especiais designados pela Organização Pan-Americana da Saúde no Brasil (OPAS) no Brasil. 


\section{VISÃO GERAL E CONTEXTOS}

Abaetetuba fica no estado do Pará, na chamada microrregião de Cametá, região do Baixo Tocantins, à margem direita do mesmo rio, já em sua foz na vasta baía de Guamá. Dista pouco mais de $100 \mathrm{~km}$ de Belém. É considerada cidadepolo da região e é a sétima mais populosa do Estado, com 156 mil habitantes e IDH, considerado apenas médio, de 0, 628

A cidade tem história antiga, remontando ao século XVII, quando, por volta de 1635 , frades capuchinhos a colonizaram, a partir de terras indígenas de etnia Samaúma, sendo o domínio português consolidado no século seguinte, cerca de 1724 .

Abaetetuba possui fácil acesso aos portos de Belém e Vila do Conde, além de todo o sul do Pará, sendo a cidade próxima a um polo industrial importante (Vila dos Cabanos), o que tem reflexos em sua economia, atualmente em expansão, com atividade econômica predominante no comércio e nos serviços. No setor agroflorestal, o município destaca-se como um dos maiores produtores de açaí do Pará, bem como de outros produtos extrativos, como o bacuri e o cupuaçu, além do cultivo da manga.

A cidade possui um panorama geográfico peculiar, compondo um arquipélago de 72 ilhas, onde existem 14 bairros e 34 localidades em ramais e estradas, nas quais dominam as dificuldades de acesso e continuidade aos serviços de saúde, com reduzida cobertura de atenção básica em saúde, de apenas $53 \%$. Além disso, observa-se uma alta taxa de mortalidade de mulheres em idade fértil, junto com altas incidências de gravidez na adolescência e de casos de sífilis e HIV/HV.

A rede municipal de saúde de Abaetetuba não dispõe de hospital próprio, possuindo apenas uma UPA, que oferece mais de 400 atendimentos/dia.

O curioso nome escolhido para o programa faz referência direta a um livro de Ana Maria Machado, no qual se aborda o tema da diversidade étnico-cultural brasileira. O projeto, inicialmente, era voltado para a questão do bullying e do racismo nas escolas, associados a altos índice de violência e exploração sexual de meninas. O município foi também alvo de repercussão nacional do episódio em que uma menina foi presa com 30 homens em uma cela, depois do qual se buscou mudanças locais de situação, com foco em justiça e solidariedade social. Menina do laço de fita, assim se transformou numa imagem emblemática da luta pelos direitos sociais.

\section{MOTIVAÇÃO E ESTRATÉGIAS}

O projeto em foco, Menina de Laço de Fita: a ternura como essência, a luta como princípio e o empoderamento como estratégia para a cidadania, tem como motivação o fato de que a cidade apresenta altos índices de mortalidade de mulheres em idade fértil, de gravidez na adolescência e de casos de sífilis, HIV e hepatites virais, ao lado de uma cobertura reduzida da Estratégia de Saúde da Família, apenas 53\%. Foram justamente os profissionais da ESF os propositores da presente iniciativa, voltada para a qualificação e melhoria da abordagem em saúde sexual e reprodutiva, levando em conta as diversidades e singularidades dos usuários, ao longo do ciclo da vida. As atividades se desenvolvem desde o mês de janeiro de 2018 e são consideradas pela equipe como em estágio avançado de execução.

Refletindo sobre o tema do projeto, cabe lembrar que "ser jovem" não significa apenas estar vivendo "a melhor fase da vida", pois ao mesmo tempo representa um período de grande risco na vida, particularmente quanto a possíveis danos à saúde. Tal risco pode se desdobrar em duas vertentes, seja a da sociabilidade, com a associada exposição à violência e ao uso de drogas; seja a da sexualidade, que traz contextos de iniciação sexual precoce, exposição às doenças sexualmente transmissíveis e gravidez precoce e indesejada. O senso comum, muitas vezes propagado também pela mídia, costuma tratar a juventude como incapaz de gerir sua vida afetiva e sexual, surgindo, com frequência, a pecha de irresponsabilidade em relação aos comportamentos juvenis. Assim, fenômenos 
considerados alarmantes, como o baixo índice de uso de contracepção entre os jovens e a gravidez na adolescência, merecem abordagens especiais, não bastando envolver apenas os jovens e as mulheres em tal condição, mas também outros grupos sociais, de risco elevado ou não. Torna-se imperativo, portanto, ampliar o foco das políticas públicas direcionadas à juventude, abordando juventude, sexualidade e reprodução sob uma ótica multidisciplinar, visando ampliar a compreensão, seja dos processos de aprendizado da sexualidade, ou das formas de interação afetivas e sexuais entre os parceiros e das prescrições dos papéis de gênero e, por fim, do desenrolar das trajetórias juvenis, em face dos eventos relativos à saúde, reprodução, sexualidade e exposição às doenças sexualmente transmissíveis.

O projeto compreende ações de saúde com adolescentes, mas também é voltado para adultos e idosos, abordando a sexualidade com valorização e respeito. O atendimento aos adolescentes é realizado sem a presença dos responsáveis, empregando-se meios facilitadores do contato, tais como oficinas de artes, teatro e dança. O programa incorpora atividades do Programa de Saúde Escolar (PSE) da Atenção Básica, com foco em temas de relevância para a população jovem e atividades voltadas para a melhoria da qualidade de vida, incluindo atendimento clínico para os casos necessários e oriundos das demandas da comunidade, com garantia de uma rede de atenção. São desenvolvidas também ações de mobilização em torno de temas como diversidade sexual, bullying, homofobia, cidadania e cultura de paz, entre outros. Além dos adolescentes, outros grupos foram contemplados, como idosos, pessoas com deficiência, população em situação de rua e LGBTI+,

Dignas de nota foram as parcerias desenvolvidas, por exemplo, com Centros de Apoio Social (CRAS, CREAS), Conselho Tutelar, Conselho Municipal de Saúde, além de outros serviços de saúde do município. Contou-se também com o apoio da Coordenação de Assistência Social do município, dos Conselhos de Direitos das Mulheres e das Crianças e a
Adolescentes, e também da Secretaria Municipal de Educação. Ocorreu apoio, ainda, de instituições diversas, tais como, rede escolar, Pastoral da Criança, universidade e voluntários.

Foi priorizado o envolvimento da população na questão do direito à saúde, sua garantia formal e na melhoria do acesso, tendo como ponto de partida a descoberta de potencialidades nos territórios de moradia e a valorização dos saberes populares, possibilitando, assim, espaços de construção de práticas de saúde que contribuíssem para a redução de iniquidades e valorização da cidadania. Da mesma forma, a qualificação e o incremento das unidades de saúde voltadas para abordagem à saúde sexual e saúde reprodutiva dos indivíduos em todas as suas diversidades e singularidades ao logo do ciclo de vida foi também incentivada, através de processos de educação em serviço, educação em saúde, mobilização social e cuidados assistenciais.

Um projeto desta natureza se justificaria, entre outras razões, pela carência de programas de acesso a métodos de concepção e anticoncepção no território de abrangência e também de serviços qualificados para a população idosa, ou portadora de necessidades especiais, além de moradores de rua, LGBTI+, homens etc. Verificou-se, também, necessidade marcante de se garantir acesso aos direitos sexuais e reprodutivos da população, dentro de um quadro alarmante de violência de gênero instituída dentro da sociedade e cultura locais. Da mesma forma, foram fatores determinantes a desumanização no parto; a violência obstétrica; a alta incidência de violência e exploração sexual infanto-juvenil; os casamentos infantis irregulares, particularmente em áreas ribeirinhas e de estrada; a homofobia; o aumento da infecção por DST, HIV e HV.

O projeto se desenvolveu mediante estratégias de: (a) promoção da inserção da população adstrita às UBS no processo de planejamento, com formatação de fluxos e medidas de acesso para a redução de barreiras; (b) educação permanente em saúde para equipe de trabalho e atividades de educação em saúde ministradas através de palestras, rodas de conversa, 
caminhadas em praças e outros;(c) ações de saúde com adolescentes, adultos e idosos para abordar temas sobre sexualidade, valorização e respeito; (d) atendimento a adolescentes sem a presença dos responsáveis, com apoio de atividades lúdicas, tais como oficinas de artes, teatro e dança, nas quais temas de relevância para os jovens eram abordados; (e) atividades focadas na melhoria da qualidade de vida; ( $f$ ) atividades de mobilização sobre temas afins: diversidade sexual, bullying, homofobia, cidadania e cultura de paz, alcançando não só adolescentes, mas também pessoas idosas, pessoas com deficiência, população em situação de rua, LGBTI+; (g) atendimento clínico para os casos necessários e oriundos das demandas da comunidade, com garantia de uma rede de atenção instituída e em parceria com CRAS, CREAS, Conselho Tutelar, Conselho de Saúde e todos os serviços de saúde do município, voltados ao cuidado; (h) outras atividades: implantação de DIU, anticoncepção de emergência em todos os serviços, obrigatoriedade da notificação de violência, prénatal do parceiro, método canguru na atenção básica, grupos de mulheres promovendo o cuidado, valorização do cuidado popular, entre outros serviços.

Além disso foi realizada uma marcha contra a violência, no âmbito do programa Março Lilás, ocorrendo ao mesmo tempo a divulgação ampla do projeto, com o lançamento de pequenos spots nas redes sociais, além da divulgação direta aos profissionais de saúde nas mídias sociais específicas. Foi possível, também, o envolvimento de rádios comunitárias e a criação de uma fan-page, na qual todas as atividades eram publicadas.
Em termos de custos, merece destaque o fato de que as diversas parcerias estabelecidas minimizaram o impacto dos mesmos, já que foram utilizados recursos já disponíveis dentro das instituições, inclusive das equipes de saúde escolar, saúde da família, NASF, Academia de Saúde. Para o alcance de algumas metas, na formação de pessoal por exemplo, a experiência foi inscrita em chamada pública (Portaria no 2.234, de 23 de julho de 2018), correspondente à "Agenda Mais Acesso, Cuidado, informação e Respeito à Saúde das Mulheres", de origem na Coordenação Nacional de Saúde da Mulher, através da qual a experiência foi selecionada e recebeu apoio financeiro de 150 mil reais para a execução de oficinas e compra de materiais para educação em saúde, mediante cumprimento de requisitos pré-estabelecidos no referido edital;

\section{RESULTADOS}

Iniciado em março de 2018, o projeto apresentou resultados no mesmo ano, com a melhoria de alguns indicadores de saúde: 7.028 atendimentos de pré-natal em 2018, contra 2.862 em 2016; 4.161 atendimentos de saúde sexual e reprodutiva, quase o dobro dos 2.507 de 2016; realização de 1.291 testes rápidos de Hepatite B, Sífilis e HIV, um aumento de mais de $100 \%$ em relação a 2016, em que foram ofertados 432 testes; e 1.880 coletas de PCCU, para prevenção do câncer de colo de útero, quando em 2016 foram realizados apenas 143 exames.

A mensuração comparativa dos resultados, antes e depois das ações em foco, ou seja, após 2018, mostrou o seguinte:

Tabela 1 - Resultados

\begin{tabular}{|l|l|r|r|r|r|}
\hline CATEGORIA DE ATENDIMENTO & \multicolumn{1}{|c|}{$\begin{array}{c}\text { FONTE DE } \\
\text { INFORMAÇÕES }\end{array}$} & $\mathbf{2 0 1 6}$ & $\mathbf{2 0 1 7}$ & $\mathbf{2 0 1 8}$ & $\begin{array}{c}\mathbf{2 0 1 9} \\
\text { (jan-jul) }\end{array}$ \\
\hline Atendimento Pré-natal & SISAB/2019 & 2.862 & 4.230 & 7.028 & 4.804 \\
\hline Saúde Sexual e Reprodutiva & SISAB/2019 & 2.507 & 3.025 & 4.161 & 1.949 \\
\hline $\begin{array}{l}\text { Teste Rápidos (Hep. B, Sifilis, } \\
\text { HIV) }\end{array}$ & SISAB/2019 & 432 & 469 & 1.291 & 1.331 \\
\hline Coleta de PCCU & SISAB/2019 & 143 & 123 & 1.880 & 705 \\
\hline
\end{tabular}

Fonte: elaborado pelos autores 
Além disso, o processo de qualificação para abordagem à saúde sexual e saúde reprodutiva por parte das equipes de atenção básica, abrangeu 21 delas; as ações de pré-natal destinadas a parceiros das mulheres inscritas foram implantadas em $100 \%$ das Unidades de Saúde; ocorreu nada menos de $40 \%$ de incremento da cobertura vacinal de HPV e Hepatite B em adolescentes, dentro das ações do PSE e a realização da semana de Saúde na Escola; a oferta de métodos contraceptivos e outros insumos para o exercício pleno da sexualidade teve acréscimo de $60 \%$; aumentou em $100 \%$ o número de unidades de saúde aptas à identificação e notificação dos casos de violência contra mulheres, idosos e crianças.

Ocorreu, ainda, o desenvolvimento de uma proposta de fóruns populares de planejamento das prioridades e atividades das ESF nos territórios, com maior qualificação de serviços de promoção e prevenção de agravos, superando a exclusividade do atendimento médico, com o decorrente empoderamento de grupos de mulheres, ações realizadas em parceria com o sindicato de trabalhadores rurais. Na mesma linha, houve incentivo à mobilização social para a testagem rápida em toda a população e, de forma associada, o acompanhamento permanente e contínuo dos projetos desenvolvidos por linhas de cuidado.

\section{DISCUSSÃO}

\section{Fatores favorecedores}

$\mathrm{Na}$ visão dos propositores a experiência é inovadora e bem-sucedida principalmente por estimular a transformação e empoderamento social com foco na garantia de direitos humanos gerais e em saúde. Houve avanço na revelação de potencialidades comunitárias, com foco nos territórios, junto com a valorização do saber popular como estratégia de enfrentamento das dificuldades de consolidação do Sistema Único de Saúde.

Foi possível ainda estimular, através do projeto, os espaços da construção de práticas de saúde redutoras de iniquidades em saúde, bem como da desigualdade social em geral. Participação popular para a redescoberta da cidadania, em uma só frase. A experiência também deu destaque e valorizou outros agentes de cuidado, não somente o profissional médico, articulando ações do governo municipal e o trabalho intersetorial.

Decisão política, equipes técnicas embasadas e articulação externa constituíram também fatores fundamentais para o sucesso da experiência.

\section{Dificuldades e obstáculos}

A situação de Abaetetuba certamente está em pleno cerne das questões colocadas em relação à Amazônia. Afinal, é uma cidade de localização estratégica, ribeirinha e remota, mas ao mesmo tempo com acesso próximo a portos, estradas de alto trânsito inter-regional, além da relativamente próxima mancha de urbanização da região da capital, Belém. Tudo isso faz da cidade um verdadeiro corredor de pessoas e interesses, que vão desde as migrações rurais urbanas características do Brasil e particularmente da Amazônia; passam pela pressão do garimpo, da grilagem, da ação madeireira e de outros interesses nem sempre legais e desembocam no crime organizado puro e simples, seja dos "sindicatos" de extermínio ou do tráfico de drogas. É em tal caldo de cultura que floresce uma cultura patriarcal, conservadora, misógina, exploradora, que valoriza pouco ou nada os direitos humanos e menospreza mais ainda a condição feminina e a da infância e adolescência.

\section{Lições aprendidas}

O desenvolvimento de um conjunto de práticas como a presente, num espaço geográfico como é o de Abaetetuba, traz, por si só, considerações ampliadas em relação a seus efeitos e reprodutibilidade. Com efeito, está fortemente colocada já há tempos, desde os anos do chamado "milagre brasileiro", pelo menos, algo que se poderia denominar "questão amazônica", caracterizada pela abertura intempestiva de tal território a interesses de diversas naturezas, incluindo desde a ideologia de integração nacional, tão cara aos militares, como a expansão das comunicações rodoviárias, com um cortejo de efeitos caracterizados, entre outros aspectos, pelo descontrole do extrativismo, principalmente madeireiro, grilagem de terras, desmatamento e, 
APS em Revista

Vol. 2, n. 3, p. 219-225 | Setembro/Dezembro-2020

ISSN 2596-3317 - DOI 10.14295/aps.v2i3.151

Goulart, F. A. A.; Jimenez, J. M. S.; Barbosa, K. C.; Lima, L. C.; Chagas, M. L. R.

particularmente, da violência, principalmente

contra populações indígenas e os mais pobres.

Assim, Menina de Laço de Fita: a ternura como essência, a luta como princípio $e \quad o$ empoderamento como estratégia para a cidadania, com seus resultados já mensuráveis, representa uma iniciativa que se reveste de enorme interesse dentro do quadro de abordagens essenciais no âmbito daquela "questão amazônica", já que foi desenvolvida diretamente na realidade local, a partir de recursos essencialmente próprios e, principalmente, com decisão política e corpo técnico autóctone. Isso, por si só, representa um fator essencial a se considerar na análise de sua potencialidade de replicação para outros ambientes da região e mesmo de fora dela.

Afinal, uma experiência que teve sucesso em um ambiente de tantas dificuldades certamente estará habilitada para uma reprodução ampliada.

\section{REFERÊNCIAS}

Cad. Saúde Pública, Rio de Janeiro, 22(7):13621363, jul, 2006.

Cad. Saúde Pública, Rio de Janeiro, 22(7):14211430, jul, 2006.

https://www.nescon.medicina.ufmg.br/bibliote ca/imagem/6358.pdf 